\title{
Radiographical Evaluation of Alveolar Bone Resorption under Fixed Dental Bridge - Part II
}

\section{Jabbar Hussein Kamel ${ }^{1}$ and Faraed Dawood Salman ${ }^{2 *}$}

${ }^{1}$ Professor in Conservative Dentistry, Head of Conservative Department, Tishik

University, Erbil, Iraq

${ }^{2}$ Professor in Department of Dental Assistant, Medical Technical Institute, Erbil

Polytechnique University, Erbil, Iraq

*Corresponding Author: Faraed Dawood Salman, Professor in Department of Dental Assistant, Medical Technical Institute, Erbil Polytechnique University, Erbil, Iraq.
Received: October 21, 2021

Published: December 08, 2021

(C) All rights are reserved by Jabbar Hussein

Kamel and Faraed Dawood Salman.

\section{Abstract}

Aims of the Study: Were evaluation of Alveolar Bone Resorption (ABR) under the fixed dental bridge (FDB) radiographically, along with considering the impact of variations like duration, the number of pontics, and the number of abutments, elaborating and expanding more about these variations.

Materials and Methods: Forty (FDBs) were included from participants attending oral diagnosis and radiology department (Dentistry department)/Tishik International University. Each (FDB) was evaluated for the duration, the number of pontics, and the number of abutments.

The orthopantomograph (OPG) was chosen as a radiographic technique to evaluate the (ABR), and measurements were done by the NewTom program.

Results: Revealed highly significant associated level of (ABR) under (FDB) alongside duration and number of pontics, while the number of abutments was found to play an insignificant vital role in ABR.

Conclusion: FDB in conjunction with both variables (increasing number of pontics and duration more than five years) induce ABR, while the number of abutments does not considerably affect ABR.

Keywords: Pontic; Abutment; Alveolar Bone Resorption (ABR); Fixed Dental Bridge (FDB)

\section{Introduction}

Fixed dental bridge was always one of the treatment options to replace one or more missing teeth. There is no doubt that fixed dental bridge (FDB) has many serving points, like reestablishing masticatory function, speech, and esthetic improvement [1]. The clinicians and patients may face failures like fractures, removal of FDB, abutment teeth sensitivity, and periodontal disease [2]. The most common of these complications is periodontal disease. That's why considering the periodontal status of abutment teeth was always a crucial point before the construction of FDB. Among these periodontal diseases, there is alveolar bone resorption, which will be the main point we focus on in this study [3]. Each of these variations has a unique influence on the alveolar bone under FDB. Several studies have been implicated in sorting out these hidden influences, and each came out with similar or different results [4]. Consequently, these studies conclude that these variations are the main discussion points between prosthodontics clinicians in meanings of the priority and role each of them on alveolar bone resorption under FDB [5].

Regarding ABR under FDB, many factors are contributing to this condition. Based on the previous occurrences in dental departments, we can divide them into four groups. 
- $\quad$ First are patient-related factors, such as socio-economic, maintaining oral hygiene, systemic diseases, age, and gender.

- Second are biomechanical factors like the number, type of pontics, number of abutments, crown root ratio, ante's law, and occlusal consideration.

- The third is the life span (duration of FDB).

- Fourth, finally, is the location (arch and margins of abutment crowns) of FDB [6].

\section{Ante's law}

Assessment of the root surface area and periodontal ligament of the abutment teeth is crucial throughout the treatment planning intended for the FDB construction. Regarding this matter, in 1926, Ante proposed a formula named "Ante's Law," which stated that the abutment-teeth root surface area has to be equivalent to or higher than the teeth intended to be replaced by pontics [7]. Considering the health of the periodontium of the abutment teeth is an obligatory fact alongside the application of Ante's law [8].

\section{Dental bridge failure}

The goals of FDB are to be preserved, improve hard-soft tissue relations, upgrade oral function, enhance esthetic, provide longterm restoration for patients and reestablish patient's comfort. Failure to achieve these aims indicates the failure of FDB treatment. John. F and Johnston (1986) classified the failure of FDB over three categories: biological, mechanical, and esthetic failures [9].

Periodontal disease, after caries, are the most common failures that arise post cementation of FDB, especially when FDBs are those having subgingival margins, ill-fitting restorations, or those with over countered retainers, the chance of periodontal diseases are in higher degrees, that is because these features are the best to induce plaque accumulation beneath FDB, the management of this failure is either by re-contouring or replacement of the restoration [8].

Periodontal response and alveolar bone resorption (ABR) under (FDB)

Knoernschild and Campbell (2000) concluded that crowns and FDBs, both poorly or appropriately fabricated, have the potential to induce the gingival inflammation under FDB [10], connecting FDB, he reported, that there is not considerable ABR in patients who regularly maintain oral hygiene [11]. Once more, Nyman and Lindhe, 1479, in their study on the outcome of prosthetic treatment following periodontal therapy, stated that either in double abutment ended or one side pontic ended (cantilever) FDBs, the alveolar bone will finely preserve its structure [12].

\section{Duration}

Valderhaugw and Burkeland, 1976 study, after five years, follow up on periodontal conditions under FDB, resulted that since the patient keeps oral hygiene and fabrication of FDB is appropriate, the periodontal changes are possible to be in small degrees [13]. Similarly, Sailer., et al. 2007, studied the outcome of zirconia FDBs following five years; results revealed no notable differences in periodontal parameters between the bridge and non-bridge side [14]. Swartz., et al. 1996, in their twenty-year follow-up study, concluded that ABR under FDB is mostly at low rates [15].

\section{Number of pontics}

Pontics can induce periodontal diseases under FDB and trigger problems like root caries, attachment loss, ABR in abutment teeth. Authors mainly point at the morphology, cleanability, and material of the pontic, as factors to induce periodontal diseases under FDB. Surprisingly, the papers hardly ever mention the number of pontics as a factor, playing a role in this condition. Meanwhile, it is well recognized by the prosthodontic department that with increasing the number of pontics, the deflection of FDB, and end in failure of the restoration. Additionally, the books of fixed prostheses reveal that FDBs with three pontics hardly have a good prognosis [16].

\section{Number of abutments}

Briggs., et al. 2012, in their specified paper, stated that old school prosthodontic departments used to recommend holding pontics on both sides, but this is not the case anymore. Today, mesial cantilever bridges, like (upper six holding upper five or canine holding lateral), result in satisfactory outcomes. However, distal cantilever still has to be constructed with carefulness. After proper diagnosis [17] concerning the additional abutments, Yang., et al. 1999 stated that supplementing long-span FDBs with other abutments will not substantially reduce the pressure on the periodontal [18]. Again Zhang., et al. 2012 concluded that further abutment units with reduced $A B$ height could not control or balance the spread of the stress on periodontal ligament structure in abutment teeth [19].

\section{Aims of the study}

- $\quad$ Evaluation of alveolar bone resorption ABR under FDB radiographically and considering the impact of variations like duration, the number of pontics, and the number of abutments.

- $\quad$ Elaborating and expanding more about these variations.

\section{Materials and Methods}

\section{Selection criteria: patients with fixed dental bridge}

The target participants of this observational, cross-sectional clinical study were patients who entered the dentistry department 
of (TIU) Tishik International University randomly selected from the diagnosis and radiology clinic intended for frequent chief complaints known in dental offices, like (pain, scaling and polishing, missing teeth, etc.), they were healthy, free from any systematic disease, when the chief complaint was taken into consideration, and regular dental diagnosis has ended, the participants with FDBs were identified, then they were respectfully asked for their consent to participate in the study.

FDBs were selected from (25) cases (14 males, 11 females). From all (40) FDBs, (63) abutments and (41) pontics were collected. Regarding the duration (28) of the FDBs was inserted less than five years, while (12) of them were more than five years.

\section{Fixed dental bridges evaluation}

After recording the participant's general information like name, age, and gender, all FDBs were evaluated for the number of pontics and abutments, and the lifespan of the FDB (duration) from the day of insertion was obtained from the participants. After that, the data were carefully registered to the specially designed case sheet (Figure 1). The orthopantomography (Figure 2) was chosen as a radiographic technique for evaluating $\mathrm{ABR}$ under FDBs.

\begin{tabular}{|c|c|c|c|}
\hline Patient's name & Age: & & $\begin{array}{l}\text { Male } \\
\text { Female }\end{array}$ \\
\hline Dental bridge & \multicolumn{3}{|c|}{$87654321 \mid 12345678$} \\
\hline $0<5$ or $\quad>5$ & & 87654321 & $1 \mid 12345678$ \\
\hline Number of pontics & $\begin{array}{l}\text { one } \\
\text { two }\end{array}$ & $\begin{array}{l}\text { three } \\
\text { four }\end{array}$ & $\begin{array}{l}\text { five } \\
\text { six }\end{array}$ \\
\hline Number of abutments & $\begin{array}{l}\text { one } \\
\text { two }\end{array}$ & $\begin{array}{l}\text { three } \\
\text { four }\end{array}$ & $\begin{array}{l}\text { five } \\
\text { six }\end{array}$ \\
\hline
\end{tabular}

Figure 1

\section{Measurements and statistical analysis}

The NewTom program (Figure 3) was used to measure the ABR from the cementoenamel junction (CEJ) to the crest of the alveolar bone. The measurements were done for both the bridge and the control side (Figure 4). The control side was those groups of teeth sitting at the different sites of the FDB within the same arch. The measurements and the recorded data on the case sheet were all categorized and listed in a table using the Microsoft Excel pro-

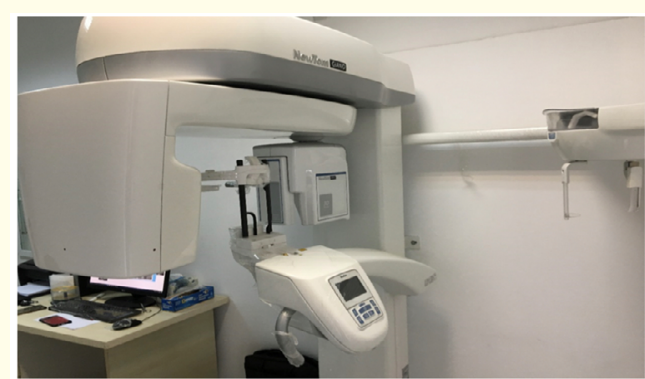

Figure 2

gram (Figure 5). Finally, all the data were analyzed using the SPSS program version 24 , and the results will be compared between patients with different variables, with a statistical significance level of $p<0.05$, the results will be presented as rates, ratios, frequencies, and percentages in tables, figures and analyzed using paired t-test.

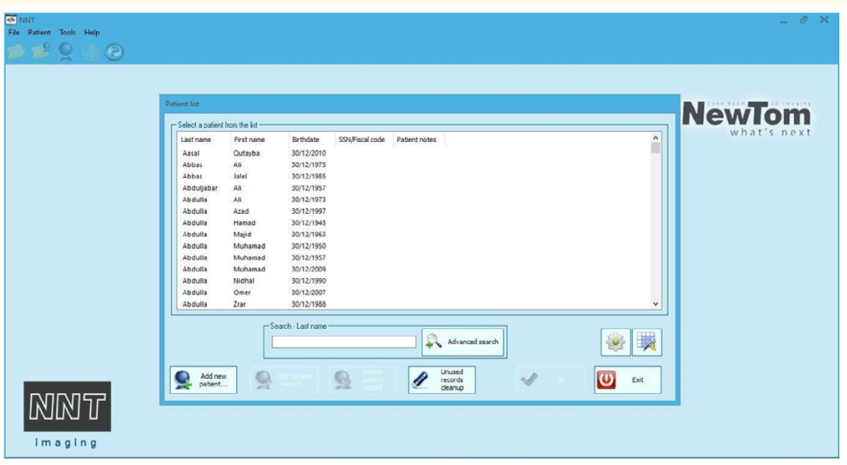

Figure 3

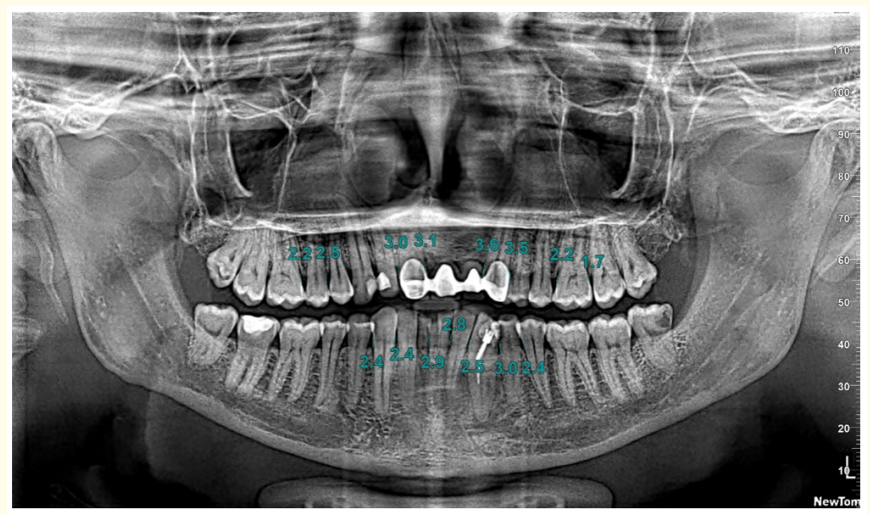

Figure 4 


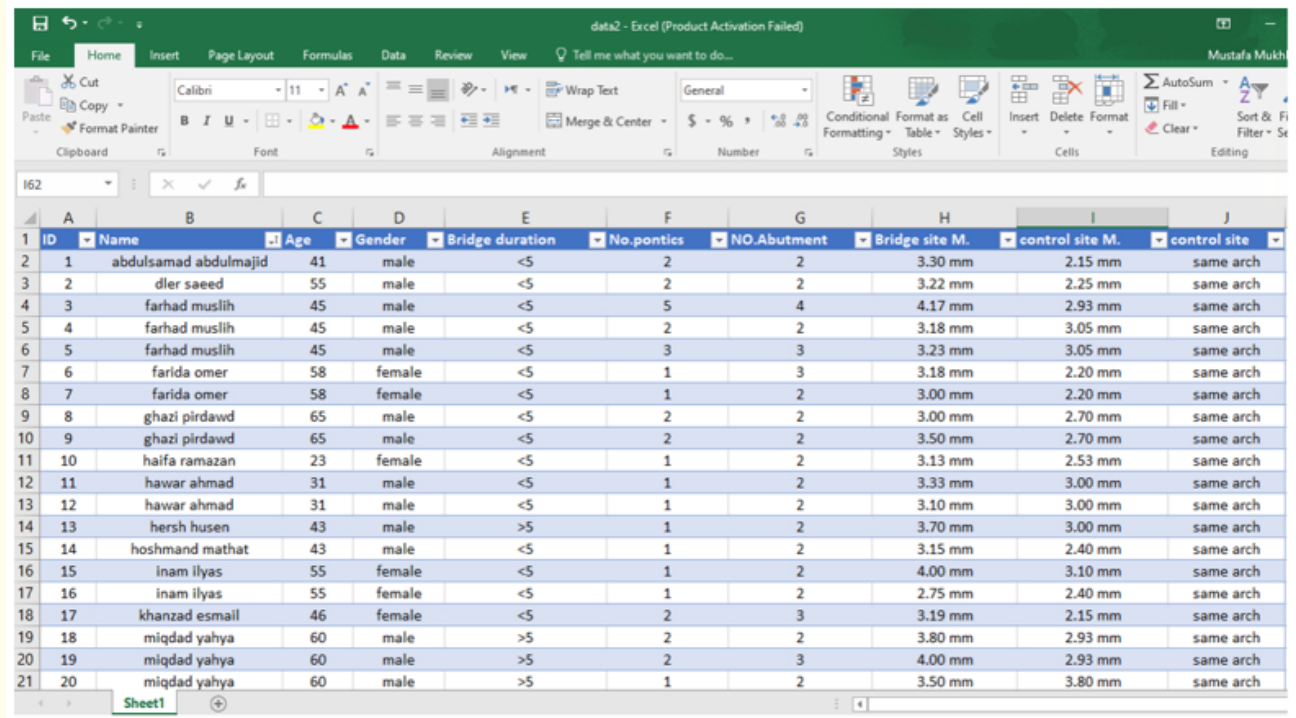

Figure 5

\section{Results}

Alveolar bone resorption under fixed dental bridge

The findings of (Table 1) indicate that there was a statistically significant difference in bone resorption between the bridge and control side. The average bone resorption of the bridge side was (3.34 mm), which was higher than that of the control side $(2.75$ $\mathrm{mm})$. A paired t-test was done to compare the two sides, and the p-value was (0.001).

\begin{tabular}{|c|c|c|c|c|c|}
\hline $\begin{array}{l}\text { Type of } \\
\text { resorption }\end{array}$ & $\mathbf{N}$ & Mean & $\begin{array}{c}\text { Std. } \\
\text { deviation }\end{array}$ & P-value & $T$ - test \\
\hline $\begin{array}{l}\text { Bridge side } \\
\text { resorption }\end{array}$ & 40 & $3.34 \mathrm{~mm}$ & $0.41 \mathrm{~mm}$ & \multirow[t]{2}{*}{0.001} & \multirow[t]{2}{*}{$\begin{array}{c}\text { Highly } \\
\text { significant }\end{array}$} \\
\hline $\begin{array}{l}\text { Control side } \\
\text { resorption }\end{array}$ & 40 & $1.75 \mathrm{~mm}$ & $\begin{array}{c}0.48 \\
\mathrm{~mm}\end{array}$ & & \\
\hline
\end{tabular}

Table 1: Comparison of bone resorption between bridge site and control site.

\section{Duration}

The findings of (Table 2) indicate a statistically significant difference in bone resorption according to the time from insertion. The average bone resorption in the FDBs inserted more than five years was (3.59 mm), which was higher than those FDBs inserted less than five years $(3.24 \mathrm{~mm})$. A paired t-test was done to compare both sides, and the p-value was (0.03).

\begin{tabular}{|l|c|c|c|c|c|c|}
\hline \multirow{2}{*}{$\begin{array}{l}\text { Bridge side } \\
\text { resorption }\end{array}$} & Duration & N & Mean & $\begin{array}{c}\text { Std. } \\
\text { Deviation }\end{array}$ & P-value & T-test \\
\cline { 2 - 5 } & $<5$ & 28 & $3.24 \mathrm{~mm}$ & $0.33 \mathrm{~mm}$ & \multirow{2}{*}{0.03} & Significant \\
\cline { 2 - 6 } & $>5$ & 12 & $3.59 \mathrm{~mm}$ & $1.48 \mathrm{~mm}$ & & \\
\hline
\end{tabular}

Table 2: Bridge side resorption according to duration.

Number of pontics

There was a moderate positive correlation between the number of pontics and bone resorption at the bridge site. The correlation coefficient (r) was (0.46), and this correlation was statistically significant, with the p-value equal to (0.003) as it is shown in (Table 3).

\begin{tabular}{|c|c|c|c|c|}
\hline Bridge side & Mean & Std. deviation & $\begin{array}{c}\text { Pearson } \\
\text { correlation }\end{array}$ & P-value \\
\cline { 2 - 5 } resorption & $3.34 \mathrm{~mm}$ & $0.41 \mathrm{~mm}$ & 0.46 & 0.003 \\
\hline
\end{tabular}

Table 3: Bridge side resorption according to the number of pontics.

\section{Number of abutments}

There was a weak positive correlation between the number of abutments and bone resorption at the bridge site. The correlation coefficient (r) was (0.25), but this correlation was statistically not significant, and the p-value was (0.11). 


\begin{tabular}{|l|c|c|c|c|}
\hline $\begin{array}{l}\text { Bridge } \\
\text { side } \\
\text { resorption }\end{array}$ & Mean & Std. deviation & $\begin{array}{c}\text { Pearson } \\
\text { correlation }\end{array}$ & P-value \\
\cline { 2 - 5 } & $3.34 \mathrm{~mm}$ & $0.41 \mathrm{~mm}$ & 0.25 & 0.11 \\
\hline
\end{tabular}

Table 4: Bridge side resorption according to the number of abutments.

\section{Discussion}

This study proved that FDB significantly induced ABR. Along with this, it proved that both dependent variables (increasing number of pontics and FDBs inserted more than five years) had significantly enhanced the ABR rate. Furthermore, this study suggested that the number of abutments does not considerably affect the ABR; this result is in accordance with that of (Moser., et al. 2002), in their 5-17 years retrospective study, revealed that ABR under FDB is not significant levels [20]. Anyhow, one must question that the study design may be the reason that puts on the differences in the results since the longitudinal retrospective design allows following up and instruction of the participants, while in the cross-sectional design, which was the choice of this study, does not allow following up with the participants. Once more, the maintenance of oral hygiene measures is the principal and efficient technique to control plaque and prevent periodontal destruction [21]. Whereas, in our study, oral hygiene measures were not obtained due to the inability to follow up with the participants.

Concerning the pontics, it is established from the prosthodontic textbooks that increasing the number of pontics results in more deflection of FDB [16]. Hence, this study verifies that this deflection can end up with ABR under FDB.

Regarding the abutments, (Nyman and Ericsson, 1982) discovered, in their study, that abutments supported the widespread of FDBs (57\%) even did not fulfill (50\%) of the teeth being replaced. However, the FDBs functioned for (8-11) years and without any periodontal destructions [22]. At this point, this may support our findings in a previous study of the ineffectiveness of the abutments regarding the ABR relation [23].

\section{Limitations}

The retrospective study design is the best approach regarding the experiments aimed to observe the complications of FDB because it allows the researchers to follow up and inspect participants.
In this study, due to the time shortage the cross-sectional design study was applied; this caused the inability to follow up the participants, which limited the chances to evaluate and control the extraneous variables, like oral hygiene measures. Meanwhile, oral hygiene measures are well known to be the most crucial factors in avoiding the complications of FDB.

\section{Conclusion}

Together with considering the limitations, this study inferred that FDBs induce ABR. Furthermore, it puts on the fact that the effectiveness of both variables (increasing number of pontics and FDB's insertion more than five years) enhances the rate of ABR; moreover, the number of abutments are ineffective in improving ABR. In conclusion, furter studies are recommended to gain more clarity regarding the ABR under FDB.

\section{Bibliography}

1. Rosenstiel SF., et al. "Contemporary fixed orthodontics ( $4^{\text {th }}$ Edition)". St. Louis: Mosby (2006).

2. Mitchell David and Laura. "Oxford Handbook of Clinical Dentistry". Oxford (2016).

3. Mitchell DA., et al. "Oxford Handbook of Clinical Dentistry (Sixth Edition)”. Oxford: Oxford University Press (2014): 268.

4. KC Basnyat S., et al. "Oral hygiene and gingival health in patients with fixed prosthodontic Appliances-A six month follow-up". Kathmandu University Medical Journal 13.52 (2015): 328-332.

5. Ottoman SM., et al. "Oral hygiene and gingival health in patients with fixed prosthodontic Appliances-A 12-month follow-up". Colloegium Antropologicum 36.1 (2012): 213-220.

6. Maglad AS., et al. "Risk Management in Clinical Practice. Part 3. Crowns and Bridges". British Dental Journal 209.3 (2010): 115.

7. Lulic M., et al. “Ante's (1926) law revisited: a systematic review on survival rates and complications of fixed dental prostheses (FDPS) on severely reduced periodontal tissue support". Clinical and Implants Research 18.3 (2007): 63-72.

8. Rosensteil SF and Land MF. "Contemporary Fixed Prosthodontics-E-Book”. Elsevier Health Science Ps 67 (2015): 786. 
9. Chandrakala V., et al. "Different Classification System for Failures in tooth supported fixed partial denture: a systematic review". International Journal of Preventive and Clinical Dental Research 6 (2019): 17-19.

10. Knoernschild KL and Campbell SD. "Periodontal tissue responses after insertion of artificial crowns and fixed partial dentures". The Journal of Prosthetic Dentistry 84 (2000): 492489.

11. Wyatt CC. "The effect of prosthodontic treatment on alveolar bone loss: a review of the literature". The Journal of Prosthetic Dentistry 80 (1998): 362-366.

12. Human S and Lindhe J. "A longitudinal study of combined periodontal and prosthetic treatment of patients with advanced periodontal disease". Journal of Periodontology 50 (1979): 163-169.

13. ValderhauGW J and Birkeland J. "Periodontal Conditions in patients 5 years following insertion of fixed prosthesis: pocket depth and loss of attachment". Journal of Oral Rehabilitation 3 (1976): 237-243.

14. Smaller I., et al. "Five-year clinical results of zirconia frames for posterior fixed partial dentures". International Journal of Prosthodontics 20 (2007): 383.

15. Swartz B., et al. "Longterm changes in marginal and periapical periodontal conditions in patients with fixed prostheses. A radiographic study". Journal of Oral Rehabilitation 23 (1996): 101-107.

16. ShillinGburg HT., et al. "Fundamentals of fixed prosthodontics". Quintessence Publishing Company (1997): 158-160.

17. Briggs P., et al. "Avoiding and managing the failure of conventional crowns and bridges". Dental Update 39 (2012): 78-84.

18. Yang HS., et al. "Finite element stress analysis on the effects of splinting in fixed partial dentures". The Journal of Prosthetic Dentistry 81 (1999): 721-728.

19. Zhang Y., et al. "Effect of double abutment absorption of alveolar bone in rigid fixed bridge on the stress distribution of abutments". Chinese Journal of Conservative Dentistry (2012): 3.

20. Moses P., et al. "Maintenance of periodontal attachment levels in prosthetically treated patients with gingivitis or moderate chronic periodontitis 5-17 years post therapy". Journal of Clinical Periodontology 29 (2002): 531-539.
21. Hammer's CH. "Success and failure of fixed bridgework". Periodontology 4 (2002): 41-51.

22. Nyman S and Ericsson I. "The capacity of reduced periodontal tissues to support fixed bridgework". Journal of Clinical Periodontology 9 (1982): 409-414.

23. Jabbar Hussein Kamel and Faraed Dawood Salman. "Radio graphical Evaluation of Bone Resorption around Fixed Prosthesis". Acta Scientific Medical Sciences 4.6 (2020).

\section{Assets from publication with us}

- Prompt Acknowledgement after receiving the article

- Thorough Double blinded peer review

- Rapid Publication

- Issue of Publication Certificate

- High visibility of your Published work

Website: www.actascientific.com/

Submit Article: www.actascientific.com/submission.php Email us: editor@actascientific.com

Contact us: +919182824667 